\title{
Glutamatergic agents for OCD and related disorders
}

\section{Christopher Pittenger, M.D., Ph.D.}

\author{
Address \\ Child Study Center, Yale University, 34 Park Street, W315, New Haven, CT 06519, \\ USA \\ Email: Christopher.pittenger@yale.edu
}

Published online: 3 July 2015

(C) Springer International Publishing AG 2015

This article is part of the Topical Collection on Anxiety, Obsessive Compulsive

and Related Disorders

Keywords Obsessive-compulsive disorder - Glutamate - NMDA receptor - Memantine - Riluzole - Ketamine . D-Cycloserine

\section{Opinion statement}

Pharmacotherapy remains inadequate for many patients with obsessive-compulsive disor$\operatorname{der}(O C D)$; there is an urgent need for alternative pharmacological strategies. Convergent evidence suggests imbalance in glutamate, the brain's primary excitatory neurotransmitter, in some patients. This has motivated interest in glutamate modulators in patients who are unresponsive to standard pharmacotherapeutic approaches. While no glutamate modulator can be considered proven as an efficacious treatment of $O C D$, promising suggestions of benefit have been reported for memantine and riluzole. The evidence is thinner for $\mathrm{N}$-acetylcysteine, but this agent's low cost and benign side effect profile make it a reasonable consideration in certain patients. Intriguing research on D-cycloserine and ketamine suggest potential benefit as well. It is notable that these agents all work by different, and in some cases opposite, mechanisms; this suggests that we have much to learn about the role of glutamate dysregulation in the etiology of OCD and of glutamate modulators in its treatment.

\section{Introduction}

Approximately $30 \%$ of the population experiences troubling obsessions or compulsions [1]. In one person in 40 , these produce a degree of impairment or distress sufficient to merit a diagnosis of obsessive-compulsive disorder, or OCD, at some point in their lives [2]. Similar phenomenology is seen in a range of other diagnoses, some of which have been categorized as "obsessivecompulsive-related disorders" in the latest edition of the Diagnostic and Statistical Manual of Mental Disorders
[3]. The associated morbidity is substantial $[4,5]$, as is the cost to society [6].

Obsessions are intrusive, stereotyped, unwanted thoughts that cause anxiety or distress; there is typically some effort to control or neutralize them. Common obsessions include concerns about contamination, fears of imminent harm, and preoccupations with order or symmetry. Compulsions are repetitive, stereotyped behaviors that are typically undertaken in an effort to 
neutralize the discomfort associated with obsessions; common examples include washing, checking, and ordering or arranging $[3,7]$. Comorbidity is common in OCD, occurring in up to $90 \%$ of patients; the most common comorbidities include depression, panic disorder, social phobia and other phobias, and alcohol use [1].

Established treatments can be of substantial benefit to many [7]. In particular, specialized cognitivebehavioral therapy and pharmacotherapy with selective serotonin reuptake inhibitors (SSRIs) are both first-line treatments, and approximately two in three patients will benefit significantly from these interventions $[7,8]$. Evidence-based options after these first-line treatments are exhausted are, however, limited $[7,9,10]$. This leaves approximately one in three patients without meaningful benefit even after optimal treatment; given the lifetime morbid risk of $2.7 \%$ [2], this translates to over three million people in the USA. Furthermore, many who are judged to be treatment responders have a partial response and/or a fluctuating course and thus continue to experience substantial morbidity. These numbers highlight the urgent need for new treatments.

Established pharmacological strategies in OCD target the brain's serotonin and dopamine neuromodulatory systems. Efforts to identify other neurochemical systems that may be involved in OCD and may represent fruitful therapeutic targets have led to investigations of other classes of medications in recent years. Increasing interest has focused on modulators of glutamate, the brain's primary excitatory neurotransmitter, as potential therapeutics in refractory disease [11•, 12-14]. While no such agent has been definitively proven to be efficacious, convergent evidence is increasingly lending credibility to this approach, and several well-tolerated agents represent reasonable alternatives once standard-of-care interventions have been exhausted.

\section{Glutamate in the central nervous system}

A comprehensive review of glutamate in the brain is far beyond our scope here, but a review of basic concepts is useful to lay the groundwork for what follows; more detailed discussions are available in recent reviews [11•]. Glutamate is an amino acid that serves as the brain's primary excitatory neurotransmitter. Its role in the brain is thus fundamentally different from that of the monoaminergic neurotransmitters. Dopamine, serotonin, and other aminergic transmitters are used by a small minority of cells that are localized in a few brain regions, mostly in the brainstem and midbrain; these cells project broadly and have important modulatory effects on diverse functional circuits throughout the brain. Glutamatergic neurons, in contrast, are embedded in practically every brain circuit; rather than being modulatory, they are appropriately thought of as constituting the circuitry itself, in most cases. This being the case, it is simplistic to speak of a "glutamate system"; the glutamate system constitutes the entire brain. Similarly, it is problematic to ask whether glutamate is excessive or reduced in OCD, or any other condition, or to seek simply to increase or decrease it using pharmacotherapy. Globally increasing glutamate would be expected to lead to seizure and neurotoxicity and globally reducing it to anesthesia. Any abnormalities in psychiatric disease are likely to be more subtle and circuit specific, and any pharmacotherapy aimed at glutamate should be thought of as modulatory, rather than simply activating or antagonizing.

Glutamate is packaged into vesicles at the axonal presynaptic terminal and is released into the synaptic cleft upon arrival of an action potential. Synaptic glutamate binds to several classes of receptors. Key among these is the $\mathrm{N}$ methyl-D-aspartate (NMDA) receptor, so named for the agonist used to identify it in early studies. The NMDA receptor has several unique characteristics, to 
which we will return below, and is a target of several glutamatergic drugs [15]. Other glutamate receptors include the AMPA and kainate receptors and the metabotropic glutamate receptors, or mGluRs. Glutamate is efficiently removed from the area around the synaptic cleft by a group of transporters, collectively known as the excitatory amino acid transporters, or EAATs [16]. EAAT1 and EAAT2 are expressed on astrocytes and perform the majority of this glutamate reuptake; EAAT3 is expressed on neurons. Low levels of glutamate persist extrasynaptically due to spillover from the synaptic cleft as well as active regulation by glial cells. These various glutamate receptors and transporters all constitute potential targets for pharmacotherapeutic agents.

A primary function of glutamate in the central nervous system is the transmission of signals from one neuron to another, but it has other roles. Glutamate binding to the NMDA receptor, in particular, is critical for the initiation of important forms of synaptic plasticity; this is mediated by the influx of calcium ions through the activated receptor. Excessive calcium influx, however, can lead to neuronal damage and even death. Calcium influx through extrasynaptic NMDA receptors appears to be particularly pernicious in this regard, which is presumably one reason that extrasynaptic glutamate concentrations are so tightly regulated. Glutamate binding to mGluR receptors regulates a variety of cellular processes, including synaptic plasticity, negative feedback modulation of glutamate release, and the regulation of local protein synthesis in dendrites.

\section{Glutamate in OCD}

Several lines of evidence suggest that glutamate imbalance may contribute to the pathophysiology of OCD. We will not review these exhaustively here, as our focus is on therapeutics; we present a brief discussion of the major themes in this literature. No single line of evidence is sufficiently clear to constitute proof that glutamate dysregulation is a major contributor to obsessions and compulsions. The pathophysiology of OCD is sure to be heterogeneous, and glutamate dysregulation may be only one contributor among many. The ability to characterize this heterogeneity may, in the future, permit informed choices of targeted pharmacological strategies.

A pair of studies examining cerebrospinal fluid (CSF) in unmedicated adult patients indicates that glutamate is excessive in a subset $[17,18]$. This is the most direct evidence for altered glutamate homeostasis in OCD. Several caveats are in order, however. First, glutamate excess was present in a minority of patients; though this was sufficient to produce a statistically significant effect of diagnosis, it may suggest that glutamate imbalance is present in only a subset of cases of OCD. If so, this may indicate that pharmacological approaches targeting glutamate may be appropriate only for that subset. Second, elevated glutamate in CSF cannot inform us as to where in the brain this glutamate comes from-it could be indicative of globally altered glutamate reuptake or some other aspect of homeostasis or of regionally specific abnormalities. Importantly, since glutamate is the principle neurotransmitter of many brain circuits, elevated glutamate could plausibly be a consequence of elevated neuronal activity that overwhelms local buffering capacity and not indicative of specific pathology in glutamatergic regulatory or signaling mechanisms. 
A second line of evidence suggesting glutamate dysregulation in OCD derives from imaging studies using magnetic resonance spectroscopy, or MRS [19•]. Early MRS studies in unmedicated pediatric OCD suggested that glutamate and related compounds are elevated in the basal ganglia and reduced in the anterior cingulate cortex $[20,21]$. Unfortunately here, too, the story has become more ambiguous with time and caveats abound. MRS has the advantage of allowing specific brain regions to be probed, but it is more difficult to interpret than direct glutamate measurement in CSF. MRS measures total tissue glutamate, including intrasynaptic and extrasynaptic as well as intracellular pools. Most studies do not distinguish between glutamate and related amino acids such as glutamine and aspartate; sometimes, even the inhibitory transmitter GABA contaminates the glutamate measure [11 $\bullet$. More recent studies have reported variable results, with the majority reporting no significant differences between patients and controls [19•]. It remains unclear whether this is because of methodological heterogeneity, clinical variability, limited statistical power, false positives in the early studies, or some other consideration.

Genetics has the potential to provide the clearest demonstration of an etiological role for glutamate dysregulation in OCD. The genetics of neuropsychiatric disorders are complex and are only slowly coming into focus [22], but several promising leads implicate polymorphisms in regulators of glutamate homeostasis and neurotransmission as risk factors. Early interest focused on the gene Slc1a1, which encodes the principle neuronal glutamate transporter, EAAT3 $[23,24]$. Mutations in this gene could plausibly alter glutamate clearance from the extrasynaptic space and thus contribute to altered neurotransmission. However, a meta-analysis of studies of the Slc1a1 gene in OCD has called the initially reported association into doubt [25], and recent genomewide association studies, though underpowered, have not identified it as a major genetic contributor $[26 \bullet, 27 \bullet \bullet]$. In those studies that do suggest an association, multiple alleles have been identified; they may have distinct effects on glutamate reuptake, and such effects may be developmentally and regionally restricted [28]. EAAT3 is responsible for a small fraction of total glutamate clearance, and so alterations in this transporter are not likely to have a major quantitative impact on brain glutamate levels [16]. On the other hand, EAAT3 has an important role in the production of antioxidants in neurons, and knockout mice exhibit cortical degeneration due to oxidative stress; this implies that abnormalities in EAAT3 or its expression may have effects other than glutamate dysregulation [29].

Recent genetic studies have suggested that polymorphisms in other glutamate-associated genes may contribute to OCD risk [22]. The synapseassociated protein 90/postsynaptic density-95-associated proteins (SAPAPs)/ disks large-associated proteins (DLGAPs), which are key components of the postsynaptic complex that anchors and spatially organizes glutamate receptors, have been a focus of significant interest. The DLGAP1 gene has emerged from recent genetic studies as a leading candidate risk gene, though it is not yet be considered proven $[26 \bullet, 27 \bullet \bullet]$. Knockout of another member of this gene family, SAPAP3, leads to phenotypes in mice that have been interpreted as recapitulating aspects of OCD [30]. Suggestive genetic associations have also been reported with the gene PTPRD, a regulator of the development of gluta-

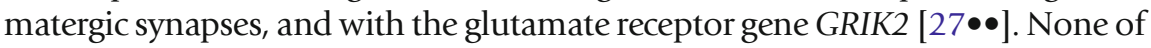
these genetic associations are yet proven, but the fact that so many glutamate- 
associated genes are emerging from genetic studies has the potential to provide perhaps the strongest evidence for a causal role for underlying abnormalities in glutamate homeostasis or neurotransmission in the pathophysiology of OCD.

\section{Glutamate pharmacology: the NMDA receptor}

With this background, we now turn to a consideration of the various glutamate modulators that have been investigated in the treatment of OCD. It is important to emphasize that in no case has the efficacy of these agents been conclusively proven, in general or in a subset of patients, in multiple well-controlled trials, and thus they should not be considered first-line treatment in place of betterproven approaches such as SSRI pharmacotherapy or expert CBT. But in the substantial fraction of patients who do not respond to conventional treatments-which is regrettably large-glutamate modulators represent an increasingly viable alternative $[7,10,11 \bullet]$. In the treatment of refractory patients, the evidence of benefit is limited but other therapeutic options are readily exhausted; clinical decisions must be made through careful balancing of risks and uncertain, but plausible, benefits.

Memantine is a noncompetitive antagonist that blocks the transmembrane ion channel pore of the NMDA receptor; it binds with relatively weak affinity and a rapid on-off rate, thus attenuating the passage of current through the channel but not blocking it as completely as agents such as ketamine and phencyclidine. Memantine is of modest benefit in intermediate Alzheimer's dementia, and it is approved in the USA and elsewhere for this purpose [31].

Evidence from CSF [17, 18] and MRS studies [21] suggesting elevated glutamate in OCD motivates the use of a glutamate antagonist in refractory disease; memantine has been investigated in this context. Early case reports and case series suggested benefit from the addition of memantine to standard treatment [11 $\bullet$,32]. Effects have been reported in children as well as adults [33]. Some diagnostic specificity to this effect is suggested by the observation, in an open-label study, that response rates are greater in OCD than in generalized anxiety disorder [34]. Two recent placebo-controlled studies of memantine have been published by groups in Iran, one in inpatients and one in outpatients, both showing very large and statistically significant treatment effects [35, 36]. These controlled studies, while promising, must be interpreted with caution; the effect sizes and response rates reported-100\% in one study-exceed what has been seen in openlabel studies of memantine or in controlled studies of any other medication in OCD, and placebo response rates were also extremely high. The generalizability of these results must be established through careful studies from other centers.

With these caveats, memantine is increasingly seen as an alternative in refractory OCD, and it is often used in this context at specialty centers [37]. Dosing has typically followed what is standard in Alzheimer's disease (10 mg twice daily), although lower doses are used in pediatric patients. 
Glycine and glycine reuptake inhibitors

Reported tolerability has generally been good, with no reported severe adverse events in OCD patients.

The NMDA receptor has an obligatory coagonist site that is bound in vivo by the amino acids glycine or D-serine; regulation of the concentration of these coagonists represents an alternative mechanism by which receptor activity can be physiologically modulated $[38,39]$ and thus a pharmacological target.

Glycine itself was investigated in a single placebo-controlled study of patients with refractory OCD [40]. Results of an analysis of completers suggested benefit of adjunctive glycine $(p=0.053)$. However, tolerability of glycine is poor, because it must be taken in very large quantities $(\sim 60 \mathrm{~g} /$ day), has an unpleasant odor and taste, and frequently causes nausea. While these characteristics make glycine a difficult agent to use clinically, the results of this pilot study suggest that other strategies modulating the coagonist site may be have therapeutic potential.

Concentrations of brain glycine are regulated in part by its reuptake by the transporters, GLY-T1 and GLY-T2. Inhibitors of these transporters can increase local glycine concentrations. Sarcosine, or N-methylglycine, a naturally occurring low-affinity GLY-T inhibitor that is available as a dietary supplement [41], has been investigated in OCD in a single uncontrolled study [42]. Improvement was seen in three different cohorts of patients, either alone or as augmentation of stable SSRI therapy.

More specific GLY-T1 inhibitors have been developed, though they are not widely available. A recently completed phase 2 study of one of these, bitopertin [43], examined efficacy in patients with OCD, as augmentation of stable SSRI treatment (NCT01674361); results have not yet been reported.

Ketamine is a noncompetitive pore-blocking antagonist of the NMDA receptor, like memantine, but with much tighter binding and very different clinical effects. It has been used clinically as an anesthetic and in pain control since the 1970s [44]; it is also used recreationally and has abuse potential. Interest in ketamine as a treatment for psychiatric disease stems from the unexpected observation that it produces rapid (though shortlived) antidepressant effects, even in severely ill and refractory patients [45, 46]. A full review of this fascinating effect, which has become a major focus in the pharmacology of depression, is beyond our scope here, but the observation has motivated interest in whether a similar effect might be seen in OCD.

An initial case report documented improvement in a medication-free patient with severe OCD after intravenous ketamine infusion [47]. A subsequent uncontrolled study in patients with severe disease, many of whom had comorbidities and were medicated, found a statistically significant but clinically trivial $8 \%$ improvement $24 \mathrm{~h}$ after ketamine infusion; among those patients with comorbid depression, there was a $72 \%$ response rate 
for depressive symptoms, providing an internal control for the efficacy of the pharmacological treatment [48•]. Subsequently, a randomized placebo-controlled study in unmedicated patients with less severe symptoms but a pattern of continuous obsessions showed a clear and clinically

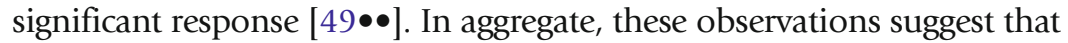
there may be some benefit from ketamine treatment in OCD, perhaps in a particular subset of patients, but whether this effect will prove to be as robust as in major depressive disorder remains to be seen.

D-Cycloserine (DCS) is a partial agonist at the glycine/D-serine site on the NMDA receptor. It has proven to be of limited benefit (in schizophrenia, where it has been extensively studied [50]) using a traditional pharmacological approach with daily dosing, perhaps because of the development of tachyphylaxis [51]. However, acute treatment has been shown to enhance certain forms of learning, by augmenting the NMDA receptor's key function in initiating mechanisms of synaptic plasticity [52]. Since cognitive-behavioral therapy, a first-line treatment for OCD and a range of other anxiety and mood disorders, represents a form of structured learning, this observation motivated the hypothesis that phasic D-cycloserine treatment in conjunction with CBT might lead to synergistic benefit [53]. Such synergy has now been demonstrated in a variety of clinical contexts [54].

Several studies have attempted the augmentation of CBT with Dcycloserine in OCD. The results have been mixed. In four early studies, three suggested benefit of D-cycloserine augmentation (not always reaching statistical significance [55-57]), while one did not [58]. Where benefit has been reported, it has generally been in the rapidity of CBT response or the efficacy of low-intensity treatment, not in the asymptotic efficacy of robust CBT; nevertheless, acceleration of CBT's effects could be of substantial clinical importance, if it facilitates engagement or reduces treatment dropouts. Details such as DCS dose and timing may critically affect the efficacy of this approach [59]. A more recent study suggests another modulator of efficacy, with significant benefit from DCS augmentation of CBT in unmedicated adults with OCD, but not in those on stable SSRI pharmacotherapy $[60 \bullet \bullet$. More work is needed to clarify the appropriate role of DCS in OCD treatment.

These four pharmacological strategies for targeting the NMDA receptor in OCD are striking for their heterogeneity. Memantine pharmacotherapy entails chronic NMDA antagonism. Ketamine, in contrast, has been used as a single infusion and thus entails acute or phasic antagonism. Glycine and GLT1 receptor blockers are presumed to augment NMDA function by increasing the availability of 
coagonist glycine and thus entail a chronic indirect enhancement of NMDA function, while D-cycloserine used in conjunction with CBT is an example of acute or phasic NMDA enhancement. It is possible that all of these varied strategies will indeed prove to be of benefit. However, it is important to note that none of these strategies are supported by unequivocal evidence, and it is equally possible that one or more of them will prove, with more data, to be inefficacious. Alternatively, it may be that all four strategies are of potential benefit, but not in the same patients. Much more research is needed to clarify these issues.

\section{Other glutamatergic agents}

Riluzole

Riluzole is a multifunctional glutamate modulator that is used in the treatment of amyotrophic lateral sclerosis [61]. Two of its mechanisms are inhibition of glutamate release through inhibition of presynaptic voltage-gated cation channels-a mechanism similar to that of anticonvulsant drugs such as lamotrigine and topiramate-and potentiation of glial reuptake of perisynaptic or extrasynaptic glutamate via glial transporters [61]. Riluzole was the first glutamate modulator to be used in refractory OCD [62], and several open-label reports have suggested substantial benefit [63, 64]. More recent controlled studies, however, are less promising. A blinded placebo-controlled study of children with OCD, some of whom were medicated and some of whom had comorbid autism, found no evidence of benefit [65]. And a controlled study of adults, all of whom were stably medicated and some of whom were treated as inpatients, found only a modest benefit in outpatients (and none in inpatients) that did not reach statistical significance in the primary analysis [66•]. What benefit there was appeared to be most significant in obsessions, not compulsions. More studies are needed to clarify whether riluzole is of substantial benefit in a subset of patients.

$\mathrm{N}$-Acetylcysteine, or NAC, is a modified amino acid with both glutamatemodulating and antioxidant properties [67]. Its low cost and relatively benign side effect profile have motivated interest in its utility across a range of neuropsychiatric conditions [68].

Data in OCD remain very thin. An early case report suggested benefit when NAC was added to standard pharmacotherapy [69]. More recently, a controlled trial from Iran has reported a large and statistically significant benefit [70]. Corroborative results from other 
sites are needed.

$\mathrm{N}$-Acetylcysteine has also been investigated in trichotillomania, an OCDrelated disorder, with mixed results. A high-quality blinded placebocontrolled trial in adults suggested clear benefit with a large effect size [71], but a similar trial in adolescents found no evidence for benefit [72]. Despite this relatively sparse evidence, interest in NAC remains strong in many quarters, because of its low cost and benign side-effect profile.

Anticonvulsant drugs work by a range of mechanisms, several acts by modulating glutamate outflow.

Topiramate interacts with voltage-gated calcium channels and thereby modulates glutamate release from axon terminals. Controlled trials have suggested modest benefit from topiramate; this may be greater for compulsions than for obsessions $[73,74]$. Side effects, especially cognitive slowing, can be problematic with this agent, which has not entered widespread use for OCD.

Lamotrigine is another anticonvulsant that has been used for a range of other indications. It reduces glutamate outflow through inhibition of certain voltage-gated sodium channels, overlapping mechanistically with one of the mechanisms of action of riluzole. Early work with lamotrigine suggested no benefit in OCD [75], but a more recent controlled trial has suggested clear benefit [76]. More research is needed.

\section{Conclusion}

Glutamate modulators have been a focus of increasing interest in the treatment of refractory OCD for over 10 years $[11 \bullet, 62]$. This being the case, it is frustrating that their appropriate use in this population remains murky and based on small studies. In refractory patients, however, in whom better-proven strategies have been exhausted, they represent a viable alternative. The evidence for benefit is perhaps strongest for memantine, as reviewed above; riluzole and lamotrigine are also viable considerations that may be of benefit for some patients. More studies of all of these agents, and of the underlying perturbations of normal glutamate neurotransmission or homeostasis, are needed to clarify which agents are of the most benefit and in which patients.

\section{Compliance with Ethics Guidelines}

\section{Conflict of Interest}

Christopher Pittenger declares no financial conflict of interest. He was site PI for a study funded by F. Hoffman La Roche, Ltd., investigating the use of the drug bitopertin in refractory OCD; this study (www.clinicaltrials. gov: NCT01674361) is briefly mentioned in the manuscript. 


\section{Human and Animal Rights and Informed Consent}

This article presents no new human or animal data, but it summarizes published work done by the author in human subjects, as described in references $63,64,66,69$, and 72 . In all cases, these studies were overseen and approved by the Yale University Human Investigations Committee, and all participants gave written informed consent prior to participation.

\section{References and Recommended Reading}

Papers of particular interest, published recently, have been highlighted as:

- Of importance

$\bullet \quad$ Of major importance

1. Ruscio AM, Stein DJ, Chiu WT, Kessler RC. The epidemiology of obsessive-compulsive disorder in the National Comorbidity Survey Replication. Mol Psychiatry. 2010;15:53-63.

2. Kessler RC, Petukhova M, Sampson NA, Zaslavsky AM, Wittchen HU. Twelve-month and lifetime prevalence and lifetime morbid risk of anxiety and mood disorders in the United States. Int J Methods Psychiatr Res. 2012;21:169-84.

3. American Psychiatric Association. and American Psychiatric Association. DSM-5 Task Force. Diagnostic and statistical manual of mental disorders: DSM-5. 5th ed. Washington: American Psychiatric Association; 2013.

4. Albert U, Maina G, Bogetto F, Chiarle A, Mataix-Cols D. Clinical predictors of health-related quality of life in obsessive-compulsive disorder. Compr Psychiatry. 2010;51:193-200.

5. Huppert JD, Simpson HB, Nissenson KJ, Liebowitz MR, Foa EB. Quality of life and functional impairment in obsessive-compulsive disorder: a comparison of patients with and without comorbidity, patients in remission, and healthy controls. Depress Anxiety. 2009;26:39-45.

6. Eaton WW, Martins SS, Nestadt G, Bienvenu OJ, Clarke $\mathrm{D}$, Alexandre P. The burden of mental disorders. Epidemiol Rev. 2008;30:1-14.

7. Koran LM, Hanna GL, Hollander E, Nestadt G, Simpson HB, American Psychiatric A. Practice guideline for the treatment of patients with obsessivecompulsive disorder. Am J Psychiatry. 2007;164:5-53.

8. G. M. Soomro, D. Altman, S. Rajagopal, and M. Oakley-Browne, "Selective serotonin re-uptake inhibitors (SSRIs) versus placebo for obsessive compulsive disorder (OCD)," Cochrane Database Syst Rev, p. CD001765, 2008.

9. Bloch $\mathrm{MH}$, Landeros-Weisenberger A, Kelmendi B, Coric V, Bracken MB, Leckman JF. A systematic review: antipsychotic augmentation with treatment refractory obsessive-compulsive disorder. Mol Psychiatry. 2006;11:622-32.

10. Pittenger C, Bloch MH. Pharmacological treatment of obsessive-compulsive disorder. Psychiatr Clin N Am. 2014;37:375-91.
11. Pittenger C, Bloch MH, Williams K. Glutamate abnormalities in obsessive compulsive disorder: neurobiology, pathophysiology, and treatment. Pharmacol Ther. 2011;132:314-32.

This review presents a more detailed review of the brain's glutamate system and of the evidence for its disruption in OCD.

12. Pittenger C, Krystal JH, Coric V. Glutamate-modulating drugs as novel pharmacotherapeutic agents in the treatment of obsessive-compulsive disorder. NeuroRx. 2006;3:69-81.

13. Ting JT, Feng G. Glutamatergic synaptic dysfunction and obsessive-compulsive disorder. Curr Chem Genomics. 2008;2:62-75.

14. Wu K, Hanna GL, Rosenberg DR, Arnold PD. The role of glutamate signaling in the pathogenesis and treatment of obsessive-compulsive disorder. Pharmacol Biochem Behav. 2012;100:726-35.

15. Mellone M, Gardoni F. Modulation of NMDA receptor at the synapse: promising therapeutic interventions in disorders of the nervous system. Eur J Pharmacol. 2013;719:75-83.

16. Zhou Y, Danbolt NC. Glutamate as a neurotransmitter in the healthy brain. J Neural Transm. 2014;121:799817.

17. Chakrabarty K, Bhattacharyya S, Christopher R, Khanna S. Glutamatergic dysfunction in OCD. Neuropsychopharmacology. 2005;30:1735-40.

18. Bhattacharyya S, Khanna S, Chakrabarty K, Mahadevan A, Christopher R, Shankar SK. Anti-brain autoantibodies and altered excitatory neurotransmitters in obsessive-compulsive disorder.

Neuropsychopharmacology. 2009;34:2489-96.

19. Brennan BP, Rauch SL, Jensen JE, Pope Jr G. A critical review of magnetic resonance spectroscopy studies of obsessive-compulsive disorder. Biol Psychiatry. 2013;73:24-31.

This review summarizes magnetic resonance spectroscopy (MRS) studies of glutamate in OCD.

20. Rosenberg DR, Mirza Y, Russell A, Tang J, Smith JM, Banerjee SP, et al. Reduced anterior cingulate glutamatergic concentrations in childhood OCD and major 
depression versus healthy controls. J Am Acad Child Adolesc Psychiatry. 2004;43:1146-53.

21. Rosenberg DR, MacMaster FP, Keshavan MS, Fitzgerald KD, Stewart CM, Moore GJ. Decrease in caudate glutamatergic concentrations in pediatric obsessivecompulsive disorder patients taking paroxetine. J Am Acad Child Adolesc Psychiatry. 2000;39:1096-103.

22. Fernandez TV, Leckman JF, Pittenger C. Genetic susceptibility in obsessive-compulsive disorder. In: Geschwind DH, Paulson HL, editors. Neurogenetics: handbook of clinical neurology, vol. 3. New York: Elsevier; 2015.

23. Dickel DE, Veenstra-VanderWeele J, Cox NJ, Wu X, Fischer DJ, Van Etten-Lee M, et al. Association testing of the positional and functional candidate gene SLC1A1/ EAAC1 in early-onset obsessive-compulsive disorder. Arch Gen Psychiatry. 2006;63:778-85.

24. Arnold PD, Sicard T, Burroughs E, Richter MA, Kennedy JL. Glutamate transporter gene SLC1A1 associated with obsessive-compulsive disorder. Arch Gen Psychiatry. 2006;63:769-76.

25. Stewart SE, Mayerfeld C, Arnold PD, Crane JR, O'Dushlaine C, Fagerness JA, et al. Meta-analysis of association between obsessive-compulsive disorder and the $3^{\prime}$ region of neuronal glutamate transporter gene SLC1A1. Am J Med Genet B Neuropsychiatr Genet. 2013;162B:367-79.

26. Stewart SE, Yu D, Scharf JM, Neale BM, Fagerness JA, Mathews CA, et al. Genome-wide association study of obsessive-compulsive disorder. Mol Psychiatry. 2013; 18:788-98.

This was the first genome-wide association study of OCD.

27.• M. Mattheisen, J. F. Samuels, Y. Wang, B. D. Greenberg, A. J. Fyer, J. T. McCracken, et al., "Genome-wide association study in obsessive-compulsive disorder: results from the OCGAS," Mol Psychiatry, May 132014.

This second genome-wide association study in OCD highlighted several glutamate-related genes as potential contributors to pathophysiology.

28. Porton B, Greenberg BD, Askland K, Serra LM, Gesmonde J, Rudnick $G$, et al. Isoforms of the neuronal glutamate transporter gene, SLC1A1/EAAC1, negatively modulate glutamate uptake: relevance to obsessivecompulsive disorder. Transl Psychiatry. 2013;3, e259.

29. Aoyama K, Suh SW, Hamby AM, Liu J, Chan WY, Chen $Y$, et al. Neuronal glutathione deficiency and agedependent neurodegeneration in the EAAC1 deficient mouse. Nat Neurosci. 2006;9:119-26.

30. Welch JM, Lu J, Rodriguiz RM, Trotta NC, Peca J, Ding JD, et al. Cortico-striatal synaptic defects and OCD-like behaviours in Sapap3-mutant mice. Nature. 2007;448:894-900.

31. Matsunaga S, Kishi T, Iwata N. Memantine monotherapy for Alzheimer's disease: a systematic review and meta-analysis. PLoS One. 2015;10, e0123289.

32. Sani G, Serra G, Kotzalidis GD, Romano S, Tamorri SM, Manfredi G, et al. The role of memantine in the treatment of psychiatric disorders other than the dementias: a review of current preclinical and clinical evidence. CNS Drugs. 2012;26:663-90.

33. Hezel DM, Beattie K, Stewart SE. Memantine as an augmenting agent for severe pediatric OCD. Am J Psychiatry. 2009;166:237.

34. Feusner JD, Kerwin L, Saxena S, Bystritsky A. Differential efficacy of memantine for obsessive-compulsive disorder vs. generalized anxiety disorder: an open-label trial. Psychopharmacol Bull. 2009;42:81-93.

35. Haghighi M, Jahangard L, Mohammad-Beigi $H$, Bajoghli H, Hafezian H, Rahimi A, et al. In a doubleblind, randomized and placebo-controlled trial, adjuvant memantine improved symptoms in inpatients suffering from refractory obsessive-compulsive disorders (OCD). Psychopharmacology (Berlin). 2013;228:633-40.

36. Ghaleiha A, Entezari N, Modabbernia A, Najand B, Askari N, Tabrizi M, et al. Memantine add-on in moderate to severe obsessive-compulsive disorder: randomized double-blind placebo-controlled study. J Psychiatr Res. 2013;47:175-80.

37. Stewart SE, Jenike EA, Hezel DM, Stack DE, Dodman $\mathrm{NH}$, Shuster L, et al. A single-blinded case-control study of memantine in severe obsessive-compulsive disorder. J Clin Psychopharmacol. 2010;30:34-9.

38. Papouin T, Ladepeche L, Ruel J, Sacchi S, Labasque M, Hanini M, et al. Synaptic and extrasynaptic NMDA receptors are gated by different endogenous coagonists. Cell. 2012;150:633-46.

39. Bergeron R, Meyer TM, Coyle JT, Greene RW. Modulation of N-methyl-D-aspartate receptor function by glycine transport. Proc Natl Acad Sci U S A. 1998;95:15730-4.

40. Greenberg WM, Benedict MM, Doerfer J, Perrin M, Panek L, Cleveland WL, et al. Adjunctive glycine in the treatment of obsessive-compulsive disorder in adults. J Psychiatr Res. 2009;43:664-70.

41. Harsing Jr LG, Juranyi Z, Gacsalyi I, Tapolcsanyi P, Czompa A, Matyus P. Glycine transporter type- 1 and its inhibitors. Curr Med Chem. 2006;13:1017-44.

42. Wu PL, Tang HS, Lane HY, Tsai CA, Tsai GE. Sarcosine therapy for obsessive compulsive disorder: a prospective, open-label study. J Clin Psychopharmacol. 2011;31:369-74.

43. Pinard E, Alanine A, Alberati D, Bender M, Borroni E, Bourdeaux P, et al. Selective GlyT1 inhibitors: discovery of [4-(3-fluoro-5-trifluoromethylpyridin-2yl)piperazin-1-yl][5-methanesulfonyl-2-((S)-2,2,2trifluoro-1-methylethoxy)phenyl]methanone (RG1678), a promising novel medicine to treat schizophrenia. J Med Chem. 2010;53:4603-14.

44. B. M. Radvansky, S. Puri, A. N. Sifonios, J. D. Eloy, and V. Le, "Ketamine-a narrative review of its uses in medicine," Am J Ther, Apr 242015.

45. Krystal JH, Sanacora G, Duman RS. Rapid-acting glutamatergic antidepressants: the path to ketamine and beyond. Biol Psychiatry. 2013;73:1133-41.

46. Berman RM, Cappiello A, Anand A, Oren DA, Heninger GR, Charney DS, et al. Antidepressant effects of 
ketamine in depressed patients. Biol Psychiatry. 2000;47:351-4.

47. Rodriguez CI, Kegeles LS, Flood P, Simpson HB. Rapid resolution of obsessions after an infusion of intravenous ketamine in a patient with treatment-resistant obsessive-compulsive disorder. J Clin Psychiatry. 2011;72:567-9.

48. Bloch MH, Wasylink S, Landeros-Weisenberger A, Panza KE, Billingslea E, Leckman JF, et al. Effects of ketamine in treatment-refractory obsessive-compulsive disorder. Biol Psychiatry. 2012;72:964-70.

This is the first systematic investigation of ketamine infusion in OCD; the authors report a statistically significant but clinically trivial effect in a group of severely affected patients.

49.•• Rodriguez CI, Kegeles LS, Levinson A, Feng T, Marcus SM, Vermes D, et al. Randomized controlled crossover trial of ketamine in obsessive-compulsive disorder: proof-of-concept. Neuropsychopharmacology. 2013;38:2475-83.

This second investigation of ketamine in OCD reported a substantial benefit in less severely affected, unmedicated patients.

50. Tuominen HJ, Tiihonen J, Wahlbeck K. Glutamatergic drugs for schizophrenia: a systematic review and metaanalysis. Schizophr Res. 2005;72:225-34.

51. Boje KM, Wong G, Skolnick P. Desensitization of the NMDA receptor complex by glycinergic ligands in cerebellar granule cell cultures. Brain Res. 1993;603:20714.

52. Walker DL, Ressler KJ, Lu KT, Davis M. Facilitation of conditioned fear extinction by systemic administration or intra-amygdala infusions of D-cycloserine as assessed with fear-potentiated startle in rats. J Neurosci. 2002;22:2343-51.

53. Ressler KJ, Rothbaum BO, Tannenbaum L, Anderson P, Graap K, Zimand E, et al. Cognitive enhancers as adjuncts to psychotherapy: use of D-cycloserine in phobic individuals to facilitate extinction of fear. Arch Gen Psychiatry. 2004;61:1136-44.

54. Rodrigues H, Figueira I, Lopes A, Goncalves R, Mendlowicz MV, Coutinho ES, et al. Does Dcycloserine enhance exposure therapy for anxiety disorders in humans? A meta-analysis. PLoS One. 2014;9, e93519.

55. Wilhelm S, Buhlmann U, Tolin DF, Meunier SA, Pearlson GD, Reese HE, et al. Augmentation of behavior therapy with D-cycloserine for obsessive-compulsive disorder. Am J Psychiatry. 2008;165:335-41. quiz 409.

56. Storch EA, Murphy TK, Goodman WK, Geffken GR, Lewin AB, Henin A, et al. A preliminary study of Dcycloserine augmentation of cognitive-behavioral therapy in pediatric obsessive-compulsive disorder. Biol Psychiatry. 2010;68:1073-6.

57. Kushner MG, Kim SW, Donahue C, Thuras P, Adson D, Kotlyar M, et al. D-Cycloserine augmented exposure therapy for obsessive-compulsive disorder. Biol Psychiatry. 2007;62:835-8.
58. Storch EA, Merlo LJ, Bengtson M, Murphy TK, Lewis $\mathrm{MH}$, Yang MC, et al. D-Cycloserine does not enhance exposure-response prevention therapy in obsessivecompulsive disorder. Int Clin Psychopharmacol. 2007;22:230-7.

59. Rothbaum BO. Critical parameters for D-cycloserine enhancement of cognitive-behaviorial therapy for obsessive-compulsive disorder. Am J Psychiatry. 2008;165:293-6.

$60 . \bullet$ E. Andersson, E. Hedman, J. Enander, D. Radu Djurfeldt, B. Ljotsson, S. Cervenka, et al., "d-Cycloserine vs placebo as adjunct to cognitive behavioral therapy for obsessive-compulsive disorder and interaction with antidepressants: a randomized clinical trial," JAMA Psychiatry, May 132015.

This study of D-cycloserine as an adjunct to cognitive behaivoral therapy in obsessive-compulsive disorder suggests benefit only in unmedicated patients.

61. Pittenger C, Coric V, Banasr M, Bloch M, Krystal JH, Sanacora G. Riluzole in the treatment of mood and anxiety disorders. CNS Drugs. 2008;22:761-86.

62. Coric V, Milanovic S, Wasylink S, Patel P, Malison R, Krystal JH. Beneficial effects of the antiglutamatergic agent riluzole in a patient diagnosed with obsessivecompulsive disorder and major depressive disorder. Psychopharmacology (Berlin). 2003;167:219-20.

63. Pittenger C, Kelmendi B, Wasylink S, Bloch MH, Coric $\mathrm{V}$. Riluzole augmentation in treatment-refractory obsessive-compulsive disorder: a series of 13 cases, with long-term follow-up. J Clin Psychopharmacol. 2008;28:363-7.

64. Coric V, Taskiran S, Pittenger C, Wasylink S, Mathalon DH, Valentine G, et al. Riluzole augmentation in treatment-resistant obsessive-compulsive disorder: an open-label trial. Biol Psychiatry. 2005;58:424-8.

65. Grant PJ, Joseph LA, Farmer CA, Luckenbaugh DA, Lougee LC, Zarate Jr CA, et al. 12-week, placebocontrolled trial of add-on riluzole in the treatment of childhood-onset obsessive-compulsive disorder. Neuropsychopharmacology. 2014;39:1453-9.

66. C. Pittenger, M. H. Bloch, S. Wasylink, E. Billingslea, R. Simpson, E. Jakubovski, et al., "Riluzole augmentation in treatment-refractory obsessive-compulsive disorder: a pilot placebo-controlled trial," J. Clin. Psychiatry, vol. in press, Aug 2015.

This study describes the first placebo-controlled investigation of riluzole in adults with OCD.

67. Dean O, Giorlando F, Berk M. N-Acetylcysteine in psychiatry: current therapeutic evidence and potential mechanisms of action. J Psychiatry Neurosci. 2011;36:78-86.

68. Deepmala, J. Slattery, N. Kumar, L. Delhey, M. Berk, O. Dean, et al., "Clinical trials of N-acetylcysteine in psychiatry and neurology: a systematic review," Neurosci Biobehav Rev, May 62015.

69. Lafleur DL, Pittenger C, Kelmendi B, Gardner T, Wasylink S, Malison RT, et al. N-Acetylcysteine augmentation in serotonin reuptake inhibitor refractory 
obsessive-compulsive disorder. Psychopharmacology (Berlin). 2006;184:254-6.

70. Afshar H, Roohafza H, Mohammad-Beigi H, Haghighi M, Jahangard L, Shokouh P, et al. NAcetylcysteine add-on treatment in refractory obsessive-compulsive disorder: a randomized, double-blind, placebo-controlled trial. J Clin Psychopharmacol. 2012;32:797-803.

71. Grant JE, Odlaug BL, Kim SW. A double-blind, placebo-controlled study of $\mathrm{N}$-acetyl cysteine plus naltrexone for methamphetamine dependence. Eur Neuropsychopharmacol. 2010;20:823-8.

72. Bloch MH, Panza KE, Grant JE, Pittenger C, Leckman JF. N-Acetylcysteine in the treatment of pediatric trichotillomania: a randomized, double-blind, placebo-controlled add-on trial. J Am Acad Child Adolesc Psychiatry. 2013;52:231-40.
73. Berlin HA, Koran LM, Jenike MA, Shapira NA, Chaplin W, Pallanti S, et al. Double-blind, placebo-controlled trial of topiramate augmentation in treatment-resistant obsessive-compulsive disorder. J Clin Psychiatry. 2011;72:716-21.

74. A. Mowla, A. M. Khajeian, A. Sahraian, A. H. Chohedri, and F. Kashkoli, "Topiramate augmentation in resistant OCD: a double-blind placebo-controlled clinical trial," CNS Spectr, Nov 12010.

75. Kumar TC, Khanna S. Lamotrigine augmentation of serotonin re-uptake inhibitors in obsessive-compulsive disorder. Aust N Z J Psychiatry. 2000;34:527-8.

76. Bruno A, Mico U, Pandolfo G, Mallamace D, Abenavoli E, Di Nardo F, et al. Lamotrigine augmentation of serotonin reuptake inhibitors in treatment-resistant obsessive-compulsive disorder: a double-blind, placebocontrolled study. J Psychopharmacol. 2012;26:1456-62. 